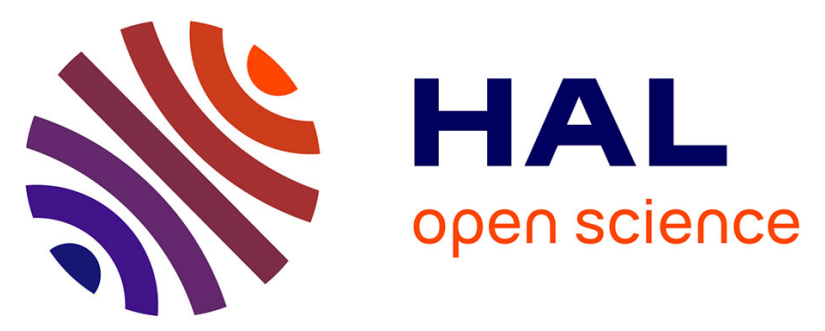

\title{
Cost-utility analysis for advanced breast cancer therapy in Germany: results of the fulvestrant sequencing model
}

Michael Patrick Lux, M. Hartmann, C. Jackisch, G. Raab, A. Schneeweiss, K. Possinger, J. Oyee, N. Harbeck

\section{- To cite this version:}

Michael Patrick Lux, M. Hartmann, C. Jackisch, G. Raab, A. Schneeweiss, et al.. Cost-utility analysis for advanced breast cancer therapy in Germany: results of the fulvestrant sequencing model. Breast Cancer Research and Treatment, 2009, 117 (2), pp.305-317. 10.1007/s10549-008-0294-9 . hal00535328

\section{HAL Id: hal-00535328 \\ https://hal.science/hal-00535328}

Submitted on 11 Nov 2010

HAL is a multi-disciplinary open access archive for the deposit and dissemination of scientific research documents, whether they are published or not. The documents may come from teaching and research institutions in France or abroad, or from public or private research centers.
L'archive ouverte pluridisciplinaire HAL, est destinée au dépôt et à la diffusion de documents scientifiques de niveau recherche, publiés ou non, émanant des établissements d'enseignement et de recherche français ou étrangers, des laboratoires publics ou privés. 


\title{
Cost-utility analysis for advanced breast cancer therapy in Germany: results of the fulvestrant sequencing model
}

\author{
Michael Patrick Lux - M. Hartmann - C. Jackisch • \\ G. Raab $\cdot$ A. Schneeweiß $\cdot$ K. Possinger $\cdot$ J. Oyee \\ N. Harbeck
}

Received: 1 December 2008/ Accepted: 23 December 2008/Published online: 8 January 2009

(C) Springer Science+Business Media, LLC. 2009

\begin{abstract}
Therapy decisions in advanced breast cancer $(\mathrm{ABC})$ increasingly require assessment not only of treatment efficacy but also of cost-effectiveness. To this end, we performed a cost-utility analysis by comparing treatment sequences including/omitting fulvestrant in a hypothetical population of hormone receptor-positive $(\mathrm{HR}+)$ postmenopausal women with $\mathrm{ABC}$. The analysis was performed from the German health care perspective. Using a first-order sequential Markov model, expected costs and utilities were calculated over a time horizon of 10 years for cohorts of patients with $\mathrm{HR}+\mathrm{ABC}$, previously treated for at least 5 years using adjuvant endocrine therapies. Utilities were primarily quantified in terms of quality adjusted life years (QALY). "Base-case" estimates of state transition rates, resource utilization, and other model parameters were derived from published evidence and expert assessment. The impacts of uncertainties in all key model parameters
\end{abstract}

Electronic supplementary material The online version of this article (doi:10.1007/s10549-008-0294-9) contains supplementary material, which is available to authorized users.

M. P. Lux (ه)

Universitäts-Brustzentrum Franken (UBF), Frauenklinik,

Universitätsklinikum Erlangen, Universitätsstrasse 21-23,

91054 Erlangen, Germany

e-mail: Michael.lux@uk-erlangen.de

M. Hartmann

Apotheke, Universitätsklinikum Jena, Jena, Germany

C. Jackisch

Klinik für Gynäkologie und Geburtshilfe, Klinikum Offenbach

$\mathrm{GmbH}$, Offenbach, Germany

G. Raab

Frauenarztpaxis mit Schwerpunkt Gynäkologische Operationen und Brustkrebschirurgie, Munich, Germany were evaluated by sensitivity analysis. Costs and benefits were discounted at 3\% annually. Including second-line fulvestrant in the treatment sequence led to greater estimated health gains (0.021 QALY) and cost savings of $€ 564$ $(\$ 745, £ 380)$ per patient, i.e. the fulvestrant-containing sequence was "dominant". The prediction of a cost savings was robust with respect to variations in all key parameters. The probability of acceptable cost-effectiveness for the fulvestrant sequence was $72 \%$ at a willingness to pay (WTP) of $€ 30,000 / \mathrm{QALY}$ ( $\$ 39,621 / \mathrm{QALY}, £ 20,198 / \mathrm{QALY}$ ); the probability was even higher at lower WTP and substantially exceeded $50 \%$ for any realistic WTP. In a representative population of women with HR+ advanced breast cancer, inclusion of fulvestrant in the treatment sequence provides a cost-effective alternative from the German health care perspective. A high probability of cost-effectiveness is maintained under variations in all key parameters. The results reflect a tendency for patients receiving fulvestrant at an early stage to maintain high quality of life for a longer interval.

\author{
A. Schneeweiß \\ Klinik für Allgemeine Frauenheilkunde und Geburtshilfe mit \\ Poliklinik, Universitätsklinikum Heidelberg, Heidelberg, \\ Germany \\ K. Possinger \\ Medizinische Klinik mit Schwerpunkt Hämatologie und \\ Onkologie (CCM), Freie Universität Berlin, Berlin, Germany \\ J. Oyee \\ Mapi Values, Bollington, UK \\ N. Harbeck \\ Frauenklinik und Poliklinik, Technische Universität München, \\ Munich, Germany
}


Keywords Breast cancer - Cost-effectiveness ·

Fulvestrant

\section{Introduction}

Until the mid-1980s, it was generally considered sufficient to assess medical services from the physician's point of view: As the service provider, the physician diagnosed the illness and initiated the appropriate intervention; as the service payer, the health insurance bodies funded the costs; and as the service recipient, the patient could be confident that the services rendered would achieve the best possible result.

A prerequisite for functioning of this system was the availability of sufficient financial resources to fund all health care services rendered [1, 2]. During the past two decades, however, these costs have risen dramatically. Part of the increase is attributable to medical-technological progress and the ensuing expanded range of diagnostic and therapeutic options. Demographic developments, particularly the increasing proportion of elderly persons within industrialized nations, as well as socio-economic factors, such as unemployment, have also contributed to this rise.

Ideally, clinical medicine with its individualized approach operates under the assumption that human life is priceless. However, due to the competition for limited resources, health care policy makers are forced to allocate resources according to priorities related to the needs of the population as a whole. Hence, the reality of medical decision making differs from the idealization by including monetary costs, which represent an additional dimension in the evaluation of medical alternatives.

In a given disease situation such as in advanced breast cancer, if different therapy options have equivalent or indistinguishable utility (efficacy and impact on quality of life), then from the societal point of view the most efficient policy would usually be to conserve resources by selecting the cheapest option. Otherwise, the utility of each therapy option needs to be taken into account before discussing cost. The willingness of society to pay for a medical intervention (drug, surgery, etc.) cannot be fairly and objectively determined without quantifying the utility of the service on an appropriate health economic basis, for example, in terms of expected quality adjusted life years gained [1].

In some countries, an assessment process along these lines constitutes an established and systematic component of the health care system. One of the best-known examples is the National Institute of Clinical Excellence (NICE) [3], set up by the British government as an independent health care agency to develop evidence-based clinical guidelines for the use of medicines in the National Health Service (NHS) in England, Wales and Northern Ireland, taking into account their value under monetary considerations. In
Germany, an independent scientific institute for quality and cost efficiency in the health care sector (IQWiG: Institut für Qualität und Wirtschaftlichkeit im Gesundheitswesen) [4] has been established within the framework of a foundation and is overseen by two federal authorities: the Federal Joint Committee (G-BA: Gemeinsamer Bundesausschuss) and the Federal Healthcare Ministry (BMG: Bundesgesundheitsministerium) [5]. The mission of this institute includes assessment of surgical and diagnostic procedures, pharmaceutical drugs, and treatment guidelines.

There is a particular need for standardized assessment models and benchmarks in advanced breast cancer. In this setting, patients place value not only on survival time, but also on quality of life. This consideration is reflected in current guidelines [6,7] for postmenopausal advanced breast cancer patients with hormone receptor-positive $(\mathrm{HR}+)$ tumors: provided they remain effective, endocrine therapies are preferred to chemotherapies due to their substantially milder toxicity profile and less severe impact on quality of life [8]. Fulvestrant is a prime therapy option in this setting because it is well tolerated, enjoys excellent compliance, and is likely to remain effective despite resistance to previous endocrine therapies. Although guidelines point toward patient benefit from sequences with fulvestrant, they do not quantitatively address the question of cost effectiveness, which is important in underpinning the interaction between the health care system and the patient. To this end, this paper presents a health economics model designed to quantify-from the specific perspective of the German health care system - the cost-effectiveness of therapeutic sequences including fulvestrant for hormone-receptor-positive, advanced breast cancer patients.

\section{Methods}

Health economics modeling approach

Expressed in general terms, the goal of a health economics model for a given disease context is to produce reliable and objective population estimates of utility, costs, and other appropriate indicators, generated by alternative courses of action (decisions and interventions) that are hypothesized to affect these indicators. The utility and cost for each patient will generally depend on the individual disease course and on responses to interventions.

In view of the complexity and variability of individual disease courses and therapy responses in advanced breast cancer, the cost-utility problem is posed here in terms of a sequential Markov model: each patient is idealized as evolving through a temporal sequence of uniquely defined (i.e. mutually exclusive) states characterizing her health, 
finally reaching the "final" or "absorbing" state (i.e. death of the patient). The particular health states defined here for advanced breast cancer are described shortly.

Events that change the state are represented within the Markov model as state transitions. In order to take the stochastic nature of events into account, many virtual patients are generated. Their state transitions are generated by random draws from appropriately parameterized probability distributions, which could depend in general on the patient's entire previous history. The current study is based on a "first-order" Markov model, i.e. the transition probabilities depend only on the immediately preceding state.

In the present model, utility is primarily measured in quality-adjusted life years (QALY's). Utility is assumed to accrue at a rate dependent on the state of health; the "quality adjustment" takes into account negative impacts on quality of life as disutility. More severe disease states are thus associated with a reduced accrual rate of utility. The reduction may be attributable both to the underlying disease and to stronger toxicities of medication; it is represented formally as a so-called "weighting factor", which ranges from "one" in the case of full health to "zero" in the case of death. Thus, two months of survival in a disease state with a utility factor of 0.4 would provide the same utility contribution as one month of survival in a state with utility factor 0.8 . Model specifics are presented below.

From the health provider's point of view, the effort to maintain or improve the state of health is usually associated with certain recurring costs (e.g., for medication) or sporadic costs (e.g., for surgery). Specific cost data for the German provider are presented below. There is often a trade-off between costs and benefits, i.e., whenever an intervention producing positive utility is associated with a positive cost difference. The incremental cost per unit of utility is known as the "incremental cost-effectiveness ratio" (ICER), calculated as the ratio of cost difference to utility gained; it is commonly measured in $€ / Q A L Y$ and $€ / L Y$ gained. When two sequences are compared, sometimes the sequence with cost savings is associated with higher utility as well; in that case, the sequence is said to be "dominant", and the optimal decision then does not depend on how much the payer is willing to pay for the utility obtained. If a treatment sequence is "dominant", then the ICER is (formally) a negative number but not reported as its meaning is ambiguous.

In most situations, uncertainties or variability in model features are possible. The term "base-case" is used here to describe model sequences with expected (or reference) parameter values. "Sensitivity analysis" refers to the process of varying relevant features or parameters in order to estimate to what degree the indicators (e.g., cost and utility) depend on departures of the assumptions from the base case [9]. Varying the parameters one by one is referred to as "one-way" sensitivity analysis. The particular base case assumed and details of the one-way sensitivity analyses are described below.

To address the key issue of uncertainties in time to progression estimates a probabilistic sensitivity analysis (PSA) was also performed. For this, a Monte Carlo simulation of 1,000 runs was performed with TTP values drawn from an appropriate probability distribution (here a beta distribution), resulting in 1,000 estimates of expected utility and cost.

The results can be visualized directly as a two-dimensional scatter plot of utility versus cost (see Results). In addition, the procedure allows one to generate a characteristic curve expressing the probability of a favorable ICER as a function of willingness to pay (WTP): this statistic is computed by varying the willingness-to-pay threshold and counting the fraction of the $\mathrm{N}$ simulations corresponding either to dominance or to an ICER lower than the threshold.

Model specifics for advanced breast cancer

A hypothetical population of postmenopausal women with the primary diagnosis of $\mathrm{HR}+$ metastatic/advanced breast cancer (ABC) was considered; patients were assumed to have previously received tamoxifen or aromatase inhibitors (AI) as adjuvant anti-hormonal therapies for at least 5 years; endocrine responsiveness was assumed to persist. Virtual patients were drawn and randomized to one of two cohorts (Fig. 1) differing in whether fulvestrant was administered as second line treatment (Cohort A) or not (Cohort B). Both sequences reflect current clinical practice in Germany.

A central aspect of the modeling problem in a Markov representation for health economics is to define appropriate, mutually exclusive health states $[10,11]$. The degree of detail used in this definition depends on the problem domain. The present model for advanced breast cancer associated health states with distinct therapy lines (Fig. 1). Based on current practice, the treatment concept for the cohort without fulvestrant thus consisted of two endocrine (AI) lines, two chemotherapy lines, and the supportive/ palliative care package administered when there are no appropriate anti-tumor treatments left for a patient, leading to a maximum of five health states in addition to the "initial" and "terminal" states. The corresponding model with fulvestrant contained these five health states together with an additional sixth health state of fulvestrant as the second line therapy.

At any given time, a patient may either remain in the current health state (i.e., therapy line) or make a transition to another state. This continuous process is approximated in Markov models as a discrete process with an appropriate time unit (known as "cycle length"). The cycle length here 
Cohort A: with fulvestrant

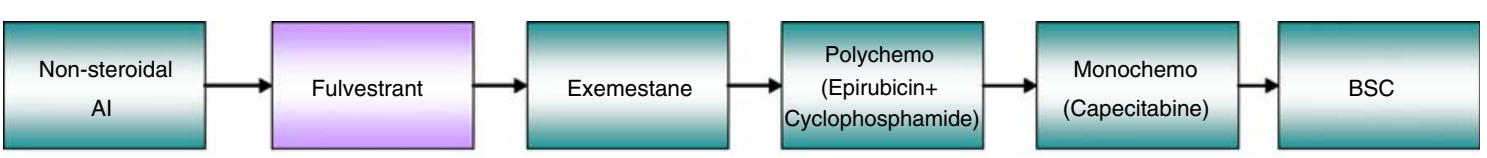

Cohort B: without fulvestrant

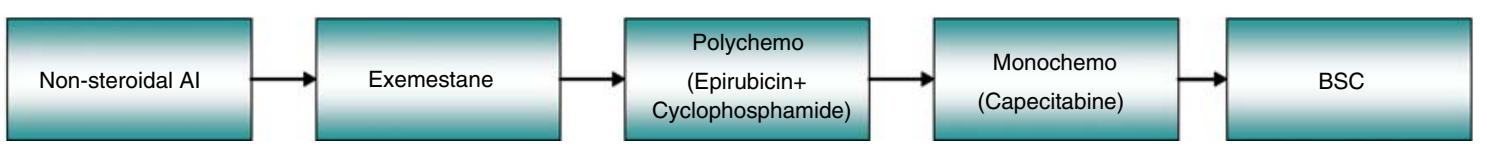

Fig. 1 Treatment sequences for the two cohorts with and without fulvestrant. AI aromatase inhibitor, BSC best supportive care; Selected chemotherapies are the ones most commonly used in Germany in the respective settings of breast cancer care

was chosen as 28 days, corresponding to one interval of fulvestrant administration. For chemotherapy and other endocrine regimens with different dosing intervals, resource use, costs and outcomes were converted as appropriate for a 28-day cycle.

Permitted state transitions are indicated in Fig. 2. In addition to transitions corresponding to the therapy concept (sequence of Fig. 1), the model includes transition probabilities from endocrine treatments to polychemotherapy (possibly skipping one or more endocrine therapies), as well as from every therapy directly to palliative care or directly to death. Transition probability distributions are related to the efficacy of each therapy as summarized below.

The Markov cohort-simulations model was implemented using Microsoft Excel ${ }^{\circledR}$ and Microsoft Visual Basic (version 6.3).

\section{Model inputs}

Model inputs to estimate transition probabilities, quality of life, and costs were derived from available sources of evidence, augmented where required by expert assessments from a panel of practising German gynaecologists and oncologists.

Transition probability distributions

The total transition rate out of a therapy state is a consequence of therapy efficacy; under the assumption that therapy changes occur when the patient suffers disease progression, this rate is characterized by time to disease progression (TTP). To obtain transition probabilities to permitted new states, estimates are also required for the probabilities of skipping one or more lines of treatment, advancing to the terminal phase, or dying while on a therapy.

The required estimates were obtained based on a systematic literature review for each therapy; if unavailable, these were elicited from the expert panel. We conducted a systematic literature review involving searches of MEDLINE, EMBASE databases, and internet search engines to identify all prospective randomized controlled trials and other experimental studies published between 1998 and 2006 regarding the treatment lines in the model sequence. Observational studies, abstracts, supplements, and unpublished studies were excluded. The medical subject heading (MeSH) "Advanced breast cancer", "postmen*", "Randomized controlled trial, "Clinical trial", "Meta-analysis" were combined with the Boolean operators 'AND' and 'OR'. TTP data were extracted from original publications and, wherever possible, results for a given treatment at a given treatment line were pooled using meta-analysis and standard statistical methods [12]. Results of the metaanalysis regarding TTP for endocrine and chemotherapy treatments are presented in Table 1.

The proportions of patients skipping a line of treatment, advancing to the terminal phase, or dying while on therapy were estimated by the panel on the basis of the available

Fig. 2 Structure of the Markov model. The different compartments represent individuals mutually exclusive health states. Arrows represent allowed transitions between these states

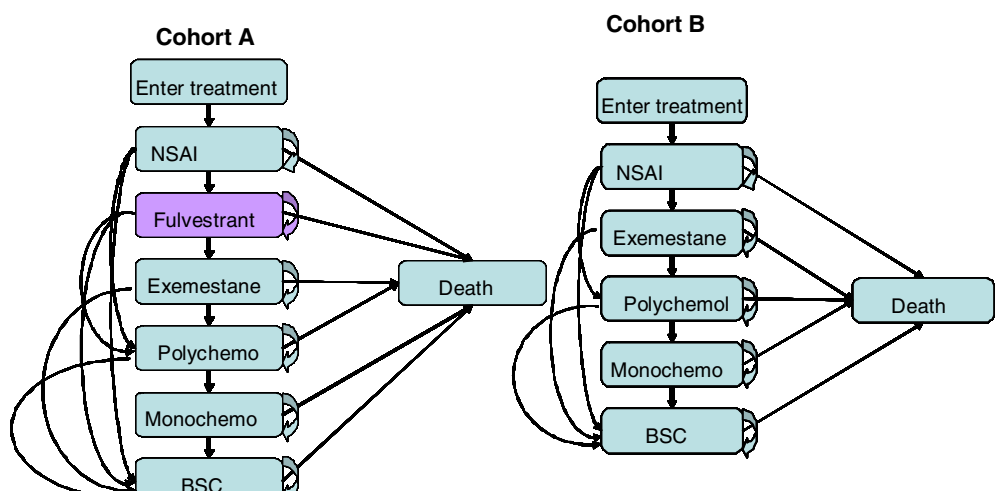


Table 1 Estimated median TTP (with upper and lower confidence intervals) by type and line of treatment

TTP time to progression

\begin{tabular}{llll}
\hline Treatment & $\begin{array}{l}\text { Treatment } \\
\text { line }\end{array}$ & $\begin{array}{l}\text { Median TTP (months) } \\
(95 \% \text { CI })\end{array}$ & Sources \\
\hline Anastrozole & $1 \mathrm{st}$ & $8.50(7.38,9.62)$ & {$[13,14]$} \\
Exemestane & $1 \mathrm{st}$ & $8.90(7.20,10.60)$ & {$[15-17]$} \\
Letrozole & $1 \mathrm{st}$ & $9.40(6.48,12.32)$ & {$[13,18,19]$} \\
Anastrozole & $2 \mathrm{nd}$ & $4.84(3.95,5.72)$ & {$[20-24]$} \\
Exemestane & $2 \mathrm{nd}$ & $4.16(3.47,4.86)$ & {$[15-17]$} \\
Fulvestrant & $2 \mathrm{nd}$ & $4.50(2.66,6.34)$ & {$[15,20,25]$} \\
Exemestane & $3 \mathrm{rd}$ & $3.72(3.09,4.35)$ & {$[15,16]$} \\
Monochemotherapy (Docetaxel) & $3 \mathrm{rd} / 4 \mathrm{th} / 5 \mathrm{th}$ & $4.20(3.36,5.04)$ & {$[26]$} \\
Monochemotherapy (Capecitabine) & $3 \mathrm{rd} / 4 \mathrm{th} / 5$ th & $3.10(2.48,3.72)$ & {$[27]$} \\
Polychemotherapy (Epirubicin + Cyclophoshamide) & $3 \mathrm{rd} / 4 \mathrm{th} / 5$ th & $3.50(2.48,3.72)$ & Expert panel \\
Polychemotherapy (Docetaxel + Capecitabine) & $3 \mathrm{rd} / 4 \mathrm{th} / 5$ th & $3.50(2.48,3.72)$ & Expert panel \\
Best supportive care/palliative care & $5 \mathrm{th} / 6 \mathrm{th}$ & $2.31(2.01,2.61)$ & Expert panel \\
\hline
\end{tabular}

literature: Estimated proportions of patients dying per line of therapy were $10 \%$ for first-line therapy, $20 \%$ for secondline therapy, $30 \%$ for third-line therapy, $40 \%$ for fourthline therapy, $60 \%$ for fifth-line therapy, and $90 \%$ for seventh-line therapy.

\section{Utility parameters}

The utility (i.e., health-related quality-of-life adjustments) associated with each treatment in the sequence was assessed by a clinical expert panel. On a 0-100 point visual analogue scale (VAS), the experts rated quality of life for a woman receiving either endocrine therapy, chemotherapy or palliative care for $\mathrm{ABC}$ during each possible therapy line. For each therapy line, the mean utilities were computed. The results, rescaled to a range from 0 to 1 , are presented in Table 2. Note that in the context of advanced breast cancer, Markov health state transitions represent disease progression, implying that any realistic model should exhibit utility decreases along the sequence. This general property is reflected in the qualitatively similar results obtained from different utility scaling systems (see below).

\section{Cost data}

Since the analysis was designed to reflect the perspective of the German health care payer, only direct costs of medical care associated with treatment of ABC were included. Thus indirect costs that would be important from a societal or patient perspective, such as productivity loss, costs to the society, additional illness-related costs arising from prolonged survival, transport costs, etc., were excluded. Costs were expressed in 2007 euros $(€)$. The direct costs for
Table 2 Utility values for different lines of treatment

\begin{tabular}{lll}
\hline Treatment line & Utility value \\
\cline { 2 - 3 } & $\begin{array}{l}\text { Cohort A } \\
\text { (with fulvestrant) }\end{array}$ & $\begin{array}{l}\text { Cohort B (without } \\
\text { fulvestrant) }\end{array}$ \\
\hline 1 & 0.89 & 0.89 \\
2 & 0.82 & 0.82 \\
3 & 0.63 & 0.53 \\
4 & 0.42 & 0.42 \\
5 & 0.36 & $\mathrm{NA}$ \\
BSC & 0.13 & 0.13 \\
Death & 0.00 & 0.00
\end{tabular}

Source: expert panel

$B S C$ best supportive care

treating $\mathrm{ABC}$ included drug acquisition costs for endocrine and chemotherapies, resource use for treatment administration and disease progression, cost of terminal care, and cost of treating adverse events associated with each sequential treatment.

Drug acquisition costs were calculated on the basis of the standard pharmacy prices for 2007 in Germany. These were extracted from the Rote Liste ${ }^{\circledR}$ [28] and are presented in Tables 3 and 4.

In addition to drugs and supportive measures, costs (per cycle length) for administration, re-evaluation, therapy monitoring, diagnostic procedures, and care in the event of disease progression were also included. The 2007 Standard Valuation Scale (Einheitliche Bewertungsmaßstab) [29] used in Germany for outpatients was the main source of resource use costs. Frequencies of monitoring and diagnostic procedures were estimated by taking into account current guidelines [30] and expert consensus: 
Table 3 Drug costs for endocrine therapy

\begin{tabular}{|c|c|c|c|c|c|c|}
\hline & Anastrozole & Fulvestrant & Exemestane & Letrozole & Tamoxifen & Megestrol acetate \\
\hline Days each unit prescribed & 28 & 28 & 30 & 28 & 30 & 30 \\
\hline Dosage & $1 \mathrm{mg}$ daily & $250 \mathrm{mg}$ every 4 weeks & $25 \mathrm{mg}$ daily & $2.5 \mathrm{mg}$ daily & $20 \mathrm{mg}$ daily & $160 \mathrm{mg}$ daily \\
\hline $\begin{array}{l}\text { Treatment cost per prescribed unit } \\
\quad(3 \text { months, } 100 \text { tablets })(€)\end{array}$ & 572.96 & 579.61 & 572.96 & 572.96 & 22.56 & $1,040.00$ \\
\hline Treatment cost per cycle (28 days) ( $€$ ) & 223.19 & 671.72 & 223.19 & 223.19 & 69.08 & 409.43 \\
\hline $\begin{array}{l}\text { Average cost for treating AE's } \\
\text { associated with therapy }(€)\end{array}$ & 101.87 & 146.61 & 156.10 & 116.95 & 87.79 & 78.87 \\
\hline
\end{tabular}

Source: Rote Liste ${ }^{\circledR}[28]$

Table 4 Drug costs for chemotherapy

\begin{tabular}{|c|c|c|c|c|}
\hline & $\begin{array}{l}\text { Monochemotherapy } \\
\text { (Capecitabine) }\end{array}$ & $\begin{array}{l}\text { Monochemotherapy } \\
\text { (Docetaxel) }\end{array}$ & $\begin{array}{l}\text { Polychemotherapy } \\
\text { (Docetaxel + Capecitabine) }\end{array}$ & $\begin{array}{l}\text { Polychemotherapy } \\
\text { (Epirubicin + Cyclophosphamide) }\end{array}$ \\
\hline Days each unit prescribed & 21 & 21 & 21 & 21 \\
\hline $\begin{array}{l}\text { Number of treatment cycles } \\
\text { (chemo) }\end{array}$ & 5 & 5 & 5 & 5 \\
\hline Dose & $\begin{array}{l}2,500 \mathrm{mg} / \mathrm{m}^{2}, \\
\mathrm{~d} 1-14, \mathrm{q} 21 \mathrm{~d} \\
\text { based on patient } \\
\text { surface area } \\
\text { of } 1.75 \mathrm{~m}^{2}\end{array}$ & $\begin{array}{c}35 \mathrm{mg} / \mathrm{m}^{2}, \mathrm{~d} 1, \mathrm{q} 7 \mathrm{~d}, \\
\text { based on patient } \\
\text { surface area of } \\
1.75 \mathrm{~m}^{2}\end{array}$ & $\begin{array}{l}\text { Capecitabine }\left(2,000 \mathrm{mg} / \mathrm{m}^{2}\right), \\
\mathrm{d} 1-14, \text { and Docetaxel } \\
\left(75 \mathrm{mg} / \mathrm{m}^{2}\right), \mathrm{d} 1, \mathrm{q} 21 \mathrm{~d}, \\
\text { based on patient surface } \\
\text { area of } 1.75 \mathrm{~m}^{2}\end{array}$ & $\begin{array}{l}\text { Epirubicin }\left(90 \mathrm{mg} / \mathrm{m}^{2}\right), \\
\mathrm{d} 1, \text { and cyclophosphamide } \\
\left(600 \mathrm{mg} / \mathrm{m}^{2}\right), \mathrm{d} 1, \mathrm{q} 21 \mathrm{~d}, \\
\text { based on patient surface } \\
\text { area of } 1.75 \mathrm{~m}^{2}\end{array}$ \\
\hline $\begin{array}{l}\text { Treatment cost per } \\
\text { prescribed unit }(€)\end{array}$ & 623.30 & 924.25 & $2,173.70$ & 956.46 \\
\hline $\begin{array}{l}\text { Treatment cost overall } \\
\text { (chemo one-off) }(€)\end{array}$ & $7,395.82$ & $9,333.37$ & $15,959.20$ & $10,016.99$ \\
\hline $\begin{array}{l}\text { Average cost for treating } \\
\text { AE's associated with } \\
\text { therapy }(€)\end{array}$ & $2,938.55$ & $3,371.35$ & $3,390.33$ & $3,534.01$ \\
\hline
\end{tabular}

Source: Rote Liste ${ }^{\circledR}$ [28]

- Re-evaluation by CT, ultrasound, or bone scintigraphy (every 3 months).

- One patient consultation for case history, assessment of health status, and for information about test results, one blood-sampling consultation and one for issuing the prescription (every 3 months).

- One GP and one breast cancer specialist visit every 4 weeks.

The following resource uses were also considered for patients under chemotherapy:

- Weekly blood-count follow-up.

- Sodium, potassium, chloride, blood glucose, GOT, GPT, creatinine, total albumin, albumin, and CRP at each administration time.

- Patients' health state, physical examination, i.v. access (e.g. port implantation), administration of chemotherapy and supportive drugs at each visit.

Table 5 presents a synopsis of the calculated costs.

Anticancer agents are known to be associated with various adverse events that may have a significant impact on patients' quality of life as well as on required health care services. In this analysis, we included both medical and health care costs for treating adverse events (AE's) for each therapy. AE's were graded according to the National Cancer Institute-Common Toxicity Criteria (NCI-CTC). Treatment and resource use for AE's were derived from expert opinion. Only AE's with an incidence of at least $5 \%$ or AE's with substantial impact on health care services were considered. Total costs were computed by multiplying the cost of each AE by its likelihood of occurring and summing.

Additional costs arising from disease progression (e.g. specialist visits and diagnostic procedures used for patient re-evaluation) and care during the terminal phase (e.g. analgesic therapy, GP home visits, nursing home visits, nutritional therapy) were also included (Table 5). These were categorized as pre-hospitalization (4 weeks), terminal phase (10 days), home care (10 days), medication, and other (6 weeks).

Analyses were performed with a 10-year time horizon. In the base case, annual discount rates of $3.0 \%$ were used for costs and benefits [31]. 
Table 5 Synopsis of the cost factors used

\begin{tabular}{lc}
\hline Resource & $\begin{array}{l}\text { Unit cost } \\
\text { per visit }(€)\end{array}$ \\
\hline GP visit & 11 \\
GP home visit & 16 \\
Specialist visit & 32 \\
Nurse home visit & 108 \\
Ultrasound scan & 28 \\
Bone scan & 73 \\
CT scan & a \\
Chest X-ray & 147 \\
Blood sample & 27 \\
Other costs associated with chemotherapy & 33
\end{tabular}

Sources: expert panel and Einheitliche Bewertungsmaßstab [29]

$G P$ General practitioner

${ }^{\text {a }}$ Weighted average costs for CT head/neck/chest/abdomen/pelvis

b Average cost including clinical biochemistry and haematology

\section{Results}

Base case

The base-case analysis (Fig. 1) compared a cohort of 1,000 $\mathrm{HR}+$ postmenopausal women with advanced breast cancer receiving a therapy sequence including second-line fulvestrant (Cohort A) to a corresponding cohort whose sequence did not include fulvestrant (Cohort B). The patient progression sequences were generated as described under Methods by drawing from estimated probability distributions describing progression rates, proportions of patients skipping therapy lines, and proportions deceased during each treatment line.
Figure 3 shows that in Cohort A fewer patients (640 vs. 756) would eventually receive polychemotherapy than in Cohort B. A similar trend was observed regarding patients progressing to mono-chemotherapy (307 in Cohort A vs. 423 in Cohort B).

Table 6 summarizes the expected costs for the base case (including costs for treatment of adverse events) and compares these for Cohorts A and B. The costs are given for each separate health (treatment) state and as a total. The two cohorts have comparable but distinct direct medical costs per patient $(€ 13,356$ vs. $€ 13,920)$ and mean survival times (24.16 months vs. 23.33 months). The treatment sequence with fulvestrant produces a mean estimated gain of 21 QALYs per 1,000 patients and estimated cost savings of $€ 564(\$ 745, £ 380)$ per patient compared to the treatment sequence without fulvestrant. Thus, the base-case sequence including fulvestrant is dominant compared to the sequence without fulvestrant as it is both less costly and more effective.

These results have a clear intuitive interpretation if one considers the cost structure of the sequences as a whole: The major cost drivers in advanced breast cancer are latestage treatments, whereas the strongest contributions to patient benefit are accrued during early-stage therapies. The longer a patient remains in an early therapy state associated with a high quality of life the greater the resulting cost-effectiveness gains.

\section{Sensitivity analysis}

Key parameters varied in one-way sensitivity analyses and their impacts on costs and utilities are summarized in Table 7. Appropriate ranges of variation for these
Table 6 Comparison of expected costs (total and for each health state), survival, and utility for the two cohorts in the base case
$B S C$ best supportive care, $L Y$ life year, NSAI non-steroidal aromatase inhibitor, $Q A L Y$ quality adjusted life year

\begin{tabular}{llll}
\hline & $\begin{array}{l}\text { Cohort A (including } \\
\text { fulvestrant) }\end{array}$ & $\begin{array}{l}\text { Cohort B (omitting } \\
\text { fulvestrant) }\end{array}$ & $\begin{array}{l}\text { Difference } \\
(\mathrm{A}-\mathrm{B})\end{array}$ \\
\hline Costs per patient by therapy & & & \\
$\quad$ NSAI (Anastrozole/Letrozole) & $€ 2,871$ & $€ 2,871$ & $€ 0$ \\
$\quad$ Fulvestrant & $€ 2,776$ & $\mathrm{NA}$ & $€ 2,776$ \\
Exemestane & $€ 406$ & $€ 1,076$ & $-€ 670$ \\
Capecitabine & $€ 4,717$ & $€ 5,880$ & $-€ 1,164$ \\
Docetaxel & $€ 1,464$ & $€ 2,124$ & $-€ 660$ \\
BSC & $€ 1,122$ & $€ 1,968$ & $-€ 846$ \\
$\quad$ Net cost per patient & $€ 13,356$ & $€ 13,920$ & $-€ 564$ \\
Mean survival (months) & 24.16 & 23.33 & 0.83 \\
LYs per patient & 2.01 & 1.944 & 0.069 \\
QALYs per patient & 1.15 & 1.13 & 0.021 \\
Cost per LY & $€ 6,645$ & $€ 7,160$ & $-€ 516$ \\
Cost per QALY & $€ 11,614$ & $€ 12,319$ & $-€ 705$ \\
Incremental cost per LY gained (A vs. B) & A dominates & & \\
Incremental cost per QALY gained (A vs. B) & A dominates & & \\
\hline
\end{tabular}




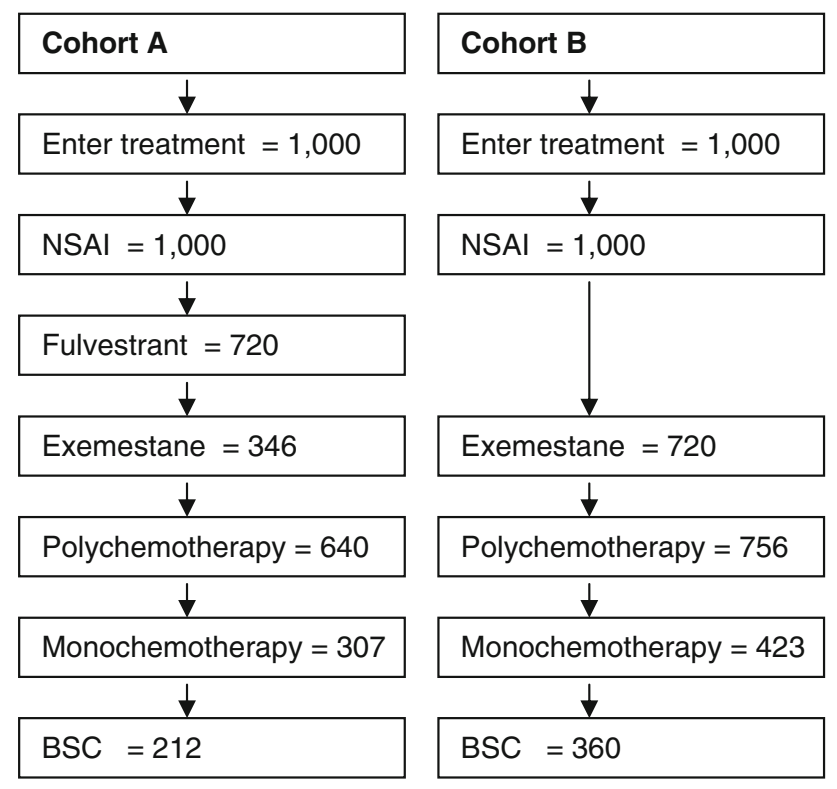

Fig. 3 Estimated number of patients with $\mathrm{HR}+$ positive $\mathrm{ABC}$ who would receive the treatment for the following drugs in sequence. $A B C$ advanced breast cancer, $B S C$ best supportive care, $H R+$ hormone receptor-positive, NSAI non-steroidal aromatase inhibitor

parameters were estimated based on clinical and economic considerations.

\section{Variation of discounting}

The practice of discounting costs and utility is subject to differing interpretations [33], even within the perspective of a given insurance carrier. The impacts of varying these discounts on costs and utilities were therefore assessed by sensitivity analysis. Results qualitatively similar to the base case were obtained when both costs and benefits were discounted either at $0 \%$ or at $6 \%$; in particular, the treatment sequence with fulvestrant still dominates (Table 7).

\section{Variation of utility values}

When utility values elicited from surveys of UK [32] or Belgian clinicians ${ }^{1}$ were utilized in the sensitivity analysis, the model showed similar results compared to the basecase analysis (Table 7), suggesting that the model was robust with regard to variations in this key parameter.

\footnotetext{
${ }^{1}$ Data on file. Utilities from Belgian clinicians were obtained from a panel of five Belgian clinicians as part of a health economic analysis for fulvestrant in the Belgian health care system. The analysis was part of an official application for reimbursement of fulvestrant by AstraZeneca Belgium to the Belgian reimbursement authority $(\mathrm{CTG}=$ Commissie Tegemoetkoming Geneesmiddelen, CRM $=$ Commission de Remboursement des Médicaments The application was submitted on March 12, 2007) 2007.
}

Variation of other parameters

Even quite substantial changes in resource costs, proportions of patients skipping treatment, proportions of patients dying at each treatment line, or chemotherapy positioning in the treatment sequence had limited effect on the ICER (Table 7).

\section{Uncertainties in TTP}

In order to characterize the effects of uncertainties in TTP, sensitivity analyses were performed with modifying the TTP from literature $\pm 20 \%$. The calculated costs varied less then $0.5 \%$. Moreover, a probabilistic sensitivity analysis (PSA) was performed using Monte Carlo methods as described above. A two-dimensional scatter plot (cost versus utility) for the results of the 1,000 simulations is presented in Fig. 4. The majority of simulations correspond to the lower right quadrant, which represents the "dominant" region for fulvestrant sequences (lower costs and higher utility), and almost all points are located in the lower half plane, corresponding to cost savings for fulvestrant sequences.

Cost-effectiveness acceptability curve

As explained above, the probabilistic sensitivity analysis allows one to generate a cost-utility acceptability curve describing the probability of a favorable ICER as a function of willingness to pay. The results are shown in Fig. 5 and indicate that there was a greater than $90 \%$ probability that the cost per QALY gained would be lower than $€ 10,000(\$ 13,207, £ 6,733)$. As yet there are no generally accepted threshold values in Germany for willingness to pay. Experience form the UK and the USA suggests, that values in the range of $£ 20-30,000$ (approximately $€ 24,000-36,800$ ) and $\$ 50,000$ (approximately $€ 34,500$ ), respectively, are generally considered acceptable for reimbursement. For these values, the probability of the fulvestrant sequence being cost-effective is at least $72 \%$.

\section{Discussion}

Efficacy measures such as degree of remission and progression-free interval are key criteria for therapy selection in advanced/metastatic breast cancer. Improved remission and progression-free interval are generally associated with longer overall survival, though quantitative relationships are complex and difficult to ascertain from the available evidence.

However, advanced breast cancer patients place value not only on overall survival, but also on present and near-term 
Table 7 Sensitivity analysis (one-way) showing impact of varying each parameter on relative utility and costs (positive numbers indicate advantage for Cohort A relative to Cohort B)

\begin{tabular}{|c|c|c|c|c|}
\hline Parameter varied & Value in base case & $\begin{array}{l}\text { Variation considered for } \\
\text { sensitivity analysis }\end{array}$ & $\begin{array}{l}\text { Utility gained } \\
\text { (QALYs per } \\
1,000 \text { patients) }\end{array}$ & $\begin{array}{l}\text { Cost savings } \\
\text { per patient }(€)^{\mathrm{a}}\end{array}$ \\
\hline None (base-case) & NA & None & 21 & 564 \\
\hline \multirow[t]{2}{*}{$\begin{array}{l}\text { Chemotherapy } \\
\text { positioning }\end{array}$} & $\begin{array}{l}\text { Polychemotherapy } \\
\text { followed by } \\
\text { monochemotherapy }\end{array}$ & $\begin{array}{l}\text { Monochemotherapy followed by } \\
\text { polychemotherapy }\end{array}$ & 17 & 510 \\
\hline & $\begin{array}{l}\text { Capecitabine as a } \\
\text { monochemotherapy }\end{array}$ & Docetaxel as a monochemotherapy & 16 & 702 \\
\hline \multirow[t]{3}{*}{ Chemotherapy regimen } & $\begin{array}{l}\text { Eprubicin plus } \\
\text { cyclophosphamide }\end{array}$ & Docetaxel plus capecitabine & 14 & 1,369 \\
\hline & $\begin{array}{l}\text { One polychemotherapy } \\
\text { and one } \\
\text { monochemotherapy }\end{array}$ & Two polychemotherapies & 16 & 1,284 \\
\hline & $\begin{array}{l}\text { One polychemotherapy } \\
\text { and one } \\
\text { monochemotherapy }\end{array}$ & Two monochemotherapies & 12 & 447 \\
\hline \multirow[t]{2}{*}{ Discount rate } & \multirow[t]{2}{*}{ Costs $3 \%$ and benefits $3 \%$} & Costs $0 \%$ and benefits $0 \%$ & 29 & 513 \\
\hline & & Costs $6 \%$ and benefits $6 \%$ & 5 & 544 \\
\hline \multirow[t]{2}{*}{ Analysis time frame } & \multirow[t]{2}{*}{10 years } & 5 years & 29 & 529 \\
\hline & & Life-time & 37 & 467 \\
\hline \multirow[t]{2}{*}{ Utility values } & \multirow[t]{2}{*}{ Expert assessment } & Belgian clinical study [19] & 15 & 564 \\
\hline & & UK clinical study [32] & 30 & 564 \\
\hline \multirow{2}{*}{$\begin{array}{l}\text { Proportion of patients } \\
\text { dying at each } \\
\text { treatment line }\end{array}$} & \multirow[t]{5}{*}{ See text } & $-20 \%$ of the base-case values & 15 & 454 \\
\hline & & $+20 \%$ of the base-case values & 20 & 609 \\
\hline \multirow{3}{*}{$\begin{array}{l}\text { Proportion skipping } \\
\text { treatment }\end{array}$} & & No skipping & 59 & 1,444 \\
\hline & & $-50 \%$ of the base-case values & 21 & 715 \\
\hline & & $+50 \%$ of the base-case values & 12 & 425 \\
\hline \multirow[t]{3}{*}{ Costs of resource use } & \multirow[t]{3}{*}{ See Tables $3,4,5,6$} & $-50 \%$ of the base-case values & 12 & 205 \\
\hline & & $+50 \%$ of the base-case values & 12 & 1,342 \\
\hline & & $\begin{array}{l}\text { Costs for resource use associated with } \\
\text { disease progression is excluded and } \\
\text { assumed to be the same as in } \\
\text { treatment specific costs }\end{array}$ & 12 & 550 \\
\hline
\end{tabular}

${ }^{a}$ Incremental costs $(€)$ per QALY gained between treatment sequence with fulvestrant and sequence without fulvestrant

quality of life. Hence a straight comparison of efficacy measures generally does not provide all the information required for patient-oriented therapy selection in this disease context [34]. For example, "degree of remission" is not necessarily the defining factor for quality of life: an endocrine therapy that can stabilize advanced disease will help to maintain quality of life at a relatively high level, even if no pronounced reduction in tumor dimensions is achieved. Efficacy measures do not include the impacts of side effects, adverse events, therapy toleration, etc. on quality of life. A similar situation prevails in most advanced cancer settings. A patient-oriented strategy [8] for evaluating the utility of oncological therapies in advanced cancer settings is to combine efficacy and quality-of-life indicators into a single utility measure, in our case "quality adjusted life years."

Only after the (expected) utility of a therapy option has been established can objective decisions regarding the appropriate cost be made [1]. To this end, cost-utility analysis (as applied here) uses the available evidence to derive estimated probability distributions for both utility and resource expenditures within a defined population. Considering alternative courses of action and alternative assumptions, one can estimate incremental costeffectiveness ratios or the probability of acceptable costs for a given willingness to pay, as demonstrated above. Hence, the analysis provides an objective basis for decision making in a complex setting. 
Fig. 4 Cost-effectiveness plane derived from the results of a cost-effectiveness analysis comparing the treatment sequence containing fulvestrant versus the sequence without fulvestrant for treating $\mathrm{ABC}$

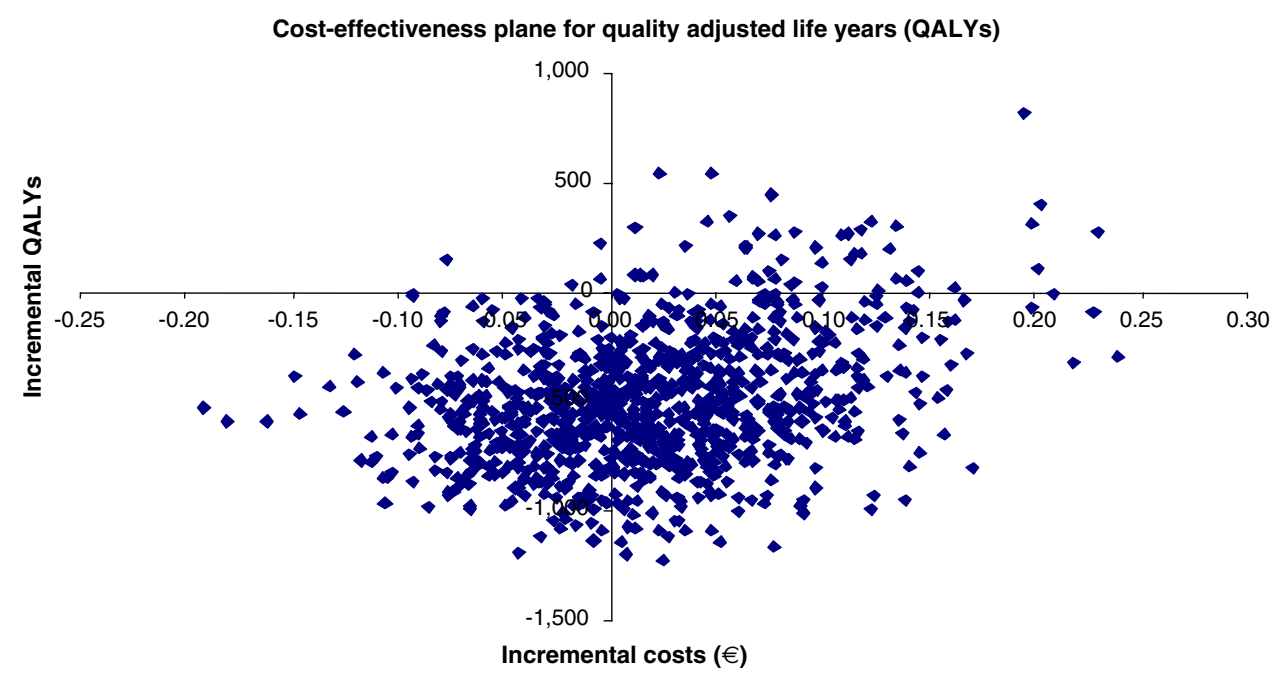

Fig. 5 Cost-effectiveness acceptability curve for inclusion of fulvestrant in the treatment of HR-positive women with $\mathrm{ABC}$

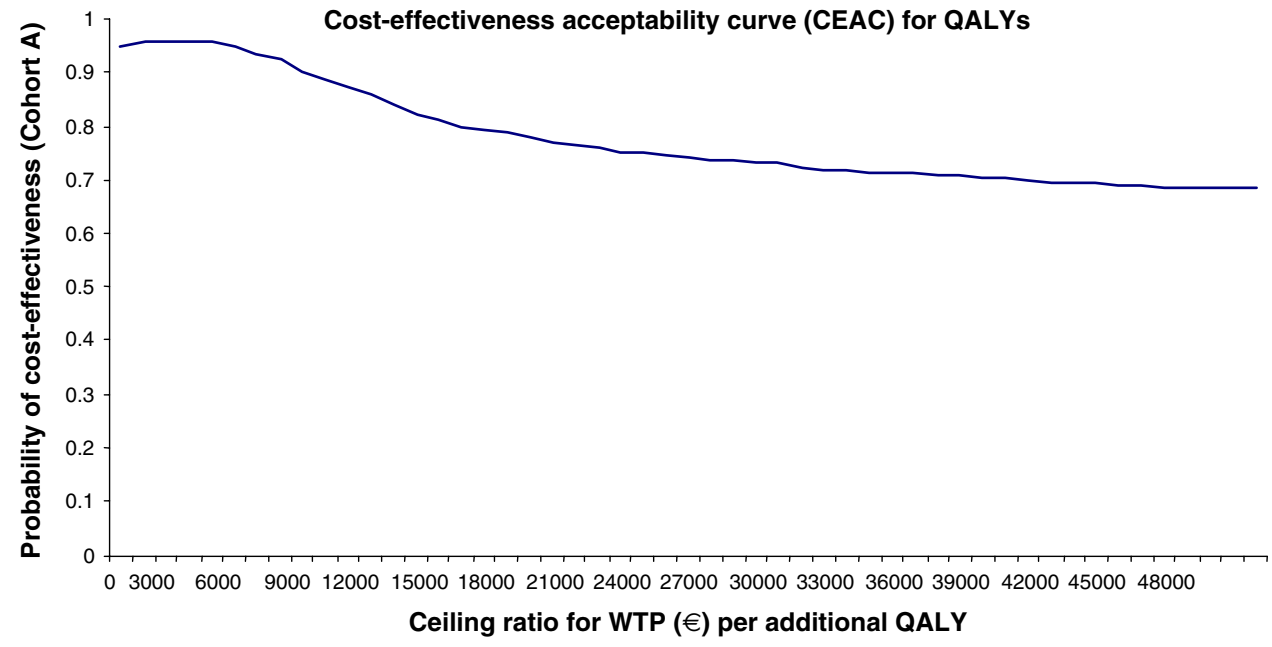

Treatment of breast cancer is a major component of health care services, since it is the most frequent cancer in women [35]. Diagnostic procedures and therapeutic procedures, particularly for $\mathrm{ABC}$, have a strong impact on budgets, leading to an increasing demand for health economic evaluation. To our knowledge, this study is the first to evaluate the cost-effectiveness of various treatment sequences in women with $\mathrm{HR}+\mathrm{ABC}$ in Germany.

Fulvestrant, an estrogen-receptor antagonist, constitutes a new form of endocrine therapy. Several clinical studies have demonstrated similar efficacy for fulvestrant in postmenopausal women with hormone-dependent advanced breast cancer (compared to an AI) with a consistently good tolerability profile [15, 20-22, 25, 36, 37]. The first clinical trial used fulvestrant after tamoxifen failure. This showed a clinical benefit in $69 \%$ which persisted up to 20 months [38]. Furthermore, an effective inhibition of tumor cell proliferation was observed in conjunction with a massive reduction of immunohistochemically detected estrogen receptors [39]. Compared to tamoxifen, there were fewer menopausal symptoms with fewer negative effects on liver, brain, and genital tract [40]. Moreover, compared to tamoxifen, fulvestrant exhibits a 100 times greater affinity for binding to the estrogen receptor. Subsequent trials investigated the use of fulvestrant in second-line therapy. Two trials reported an effectiveness equivalent to that of anastrozole [21]. In the context of the randomized phase-III EFECT trial, the effectiveness of fulvestrant in metastatic breast cancer patients who had been pre-treated with nonsteroidal AI's was compared to that of exemestane [15]. This showed comparable effectiveness with clinical benefit of $32.2 \%$ vs. $31.5 \%$ and response duration of 13.5 months vs. 9.8 months, respectively. Warm et al. [41] enrolled 848 postmenopausal women with ER+ advanced breast cancer, who had relapsed during or after adjuvant anti-estrogen treatment, or with a disease progression under an antiestrogen therapy, in an In Practice Evaluation Programme (IPEP) with fulvestrant therapy. In this study, $78 \%$ of the patients had one or more prior palliative therapies. Estimated 9-month overall survival was $89 \%$ and 9-month 
event-free survival was $71 \%$. Tolerability was judged as good to very good by the majority of both specialists and patients with stable values at 3,6 and 9 months.

The combination of efficacy and tolerability formed the basic assumption of this model. This combination provides the opportunity to maintain quality of life, delay or avoid chemotherapies with serious side-effects, and prolong endocrine therapy by adding an additional endocrine therapy step (i.e. fulvestrant). In this Markov model formulated here for HR + advanced breast cancer in the German context, therapy sequences including fulvestrant therapy had both improved utility and lower costs than those omitting fulvestrant, i.e. in Health Economic terminology, fulvestrant sequences were "dominant". This result held not only for the base case, but also for all one-way sensitivity analyses. The base-case sequence with second-line fulvestrant resulted in an estimated utility gain of 21 QALYs per 1,000 patients and estimated cost saving of $€ 564$ per patient compared to the treatment sequence without fulvestrant. Cost savings due to including fulvestrant in the therapy sequence were very likely as indicated by the cost-effectiveness acceptability curve: the probability of acceptable cost-effectiveness exceeded 50\% for any realistic level of "willingness to pay" (WTP) and was about $75 \%$ for WTP $=€ 30,000 / \mathrm{QALY}$. Dominance of the fulvestrant-containing sequence held irrespective of the kind of chemotherapeutic agents used or the use of monoas opposed to polychemotherapy. In essence, the initial increase in costs of introducing fulvestrant into the existing $\mathrm{ABC}$ treatment sequence in Germany is more than offset by direct savings due to reduced or delayed use of chemotherapy and indirect savings of resources required for treating chemotherapy-associated adverse events.

In a recent analysis, Cameron et al. [42] used a similar sequential model to evaluate the use of fulvestrant as second-line therapy in the UK context. According to their model, integration of fulvestrant would lead to a gain of 53.5 QALYs at an additional cost of $£ 716$ per 1,000 women with HR+ advanced breast cancer. Using the UK utility values in our sensitivity analysis resulted in a gain of 30.0 QALYs at an additional cost of $€ 564$ per 1,000 women. This minor variation in the overall results suggests that the model is robust for the utility parameter. Although there are considerable differences between the UK and the German health systems, the results of the two studies suggest that the underlying cost-saving mechanism for fulvestrant may be consistent across different health systems.

Maintenance of quality of life is still the most important goal in the area of palliative medicine. The present analysis placed a special focus on the occurrence of side-effects with a demonstrable influence on quality of life. In this connection, available endocrine therapy options were reviewed for side-effects (e.g. bone pain, anemia, constipation, diarrhea, thromboembolic events, etc.). These side effects were then connected with appropriate supportive therapies according to the NCI-CTC criteria and corresponding guidelines by the expert panel in a consensus procedure, and subsequently factored with costs. The identical consensus procedure was also applied to chemotherapy-related side-effects (e.g. alopecia, anorexia, asthenia, infections, diarrhea, neutropenia, etc.). Numerous side-effects of chemotherapy can result in patient hospitalization, thus reducing quality of life by social isolation even further. Thus, as a result of the rise in costs, the cost benefit ratio of chemotherapy compared to that of fulvestrant was influenced in a negative way.

All modeling studies are subject to uncertainties arising from the limited quality of available clinical evidence. For example, the external (out-of-sample) validity of clinical trial results may be limited when applied to day-to-day practice in advanced breast cancer, particularly whenever clinical practice differs from the trial protocol. These uncertainties can be at least partially captured and quantified by directly addressing the source of uncertainty and performing one-way and probabilistic sensitivity analyses as described above.

Some key uncertainties that could affect the results need to be noted. First, published evidence for efficacy (TTP) of third to fifth line chemotherapy in $\mathrm{ABC}$ is rarely available: most available studies have evaluated first or second-line treatment, and very few have considered third-line treatment. Some parameters were therefore estimated by expert consensus, if none were available from the literature. The inherent uncertainties around the TTP were addressed by the method of probabilistic sensitivity analysis, captured in the model by fitting a distribution around TTP. Second, our baseline analysis assumed a time frame of 10 years. The corresponding uncertainties were addressed by performing sensitivity analysis on time frame parameters, i.e. 2 years, 5 years, and life-time frames.

According to our model assumptions, designed for the German context, in a representative population of women with HR+ advanced breast cancer, inclusion of fulvestrant in the treatment sequence provides a cost-effective therapy concept. The dominance (cost effectiveness and better utility) of the fulvestrant option holds not only for the base case (second-line fulvestrant) but also for a third-line fulvestrant option. Moreover, a high probability of costeffectiveness is maintained under variations in all key parameters and persists irrespective of the type and mode of chemotherapy selected. The results reflect a tendency for patients receiving fulvestrant to remain longer in earlier therapy states associated with higher quality of life. By this, life time with endocrine therapy with several endocrine drugs can be extended and later therapy stages with a 
more detrimental impact on quality of life and higher costs, such as chemotherapy, can be delayed or avoided.

As a result of medical progress and changes in economic, political, and demographic factors affecting most countries, medical costs are becoming an increasingly important factor in decision making. In Germany, health care expenditures have become a controversial public issue, but the discussion generally has focused on costs rather than cost/benefit ratios. However, rational decisions concerning payment cannot be made without ascertaining the potential value of the health services rendered. In order to achieve maximum benefit for patients while taking limited resources into account, medical economic models are likely to play an increasingly important role in health policy, particularly in the market approval process for new treatment concepts in advanced disease settings. There is a strong need for the stakeholders in health care to integrate the parameters required for determining cost effectiveness into clinical trial designs. Clinical trials in advanced forms of cancer could address the problem of cost-effectiveness by evaluating both traditional efficacy measures (e.g., as primary endpoints) and measures of quality of life (e.g., as secondary endpoints) as well as capturing data on resource use. More precise and extensive data on these parameters could significantly reduce the residual uncertainties in expected cost/benefit ratios.

Acknowledgements The authors would like to thank Dr. Ronald Kates for his professional editing, helpful comments and perceptive criticisms of the manuscript. This work was supported by an unrestricted grant from AstraZeneca Germany.

\section{References}

1. Porzsolt F, Klinische Ökonomik (2003) Die ökonomische Bewertung von Gesundheitsleistungen aus der Sicht des Patienten. In: Porzsolt F, Williams AR, Kaplan RM, Klinische Ökonomik (eds) Effektivität und Effizienz von Gesundheitsleistungen. Ecomed, Landsberg, pp 17-40

2. Health and Health Care 2010 (2000) The forecast, the challenge by the Institute for the Future. Jossey-Bass, San Francisco, CA, ISBN 0-7879-5348-2

3. National Institute for Clinical Excellence (NICE) (2008) http://www. nice.org.uk

4. Institut für Qualität und Wirtschaftlichkeit im Gesundheitswesen (IQWiG) (2008) http://www.iqwig.de/index.2.en.html

5. Federal Ministry of Health (Bundesgesundheitsministerium, BMG FHM (2008) http://www.bmg.bund.de/cln_041/DE/Home/ homepage_node.html_nnn=true

6. Beslija S, Bonneterre J, Burstein $\mathrm{H}$, Cocquyt V, Gnant $\mathrm{M}$, Goodwin P et al (2007) Second consensus on medical treatment of metastatic breast cancer. Ann Oncol 18(2):215-225

7. AGO Guideline (2008) http://www.ago-online.de/index/php?lang= de\&sote=mamma_guide08_1_1\&topic=mamma_guide

8. Simons WR, Jones D, Buzdar A (2003) Cost-effectiveness of anastrozole versus tamoxifen as first-line therapy for postmenopausal women with advanced breast cancer. Clin Ther 25(11):2972-2985
9. Schackman BR, Gold HT, Stone PW, Neumann PJ (2004) How often do sensitivity analyses for economic parameters change cost-utility analysis conclusions? Pharmacoeconomics 22(5): 293-300

10. Briggs A, Sculpher M (1998) An introduction to Markov modelling for economic evaluation. Pharmacoeconomics 13(4):397-409

11. Sonnenberg FA, Beck JR (1993) Markov models in medical decision making: a practical guide. Med Decis Making 13:322-338

12. DerSimonian R, Laird N (1986) Meta-analysis in clinical trials. Control Clin Trials 7(3):177-188

13. Rose C, Vtoraya O, Pluzanska A, Davidson N, Gershanovich M, Thomas R et al (2003) An open randomised trial of second-line endocrine therapy in advanced breast cancer comparison of the aromatase inhibitors letrozole and anastrozole. Eur J Cancer 39(16):2318-2327

14. Nabholtz JM, Falkson C, Campos D, Szanto J, Martin M, Chan S et al (2003) Docetaxel and doxorubicin compared with doxorubicin and cyclophosphamide as first-line chemotherapy for metastatic breast cancer: results of a randomized, multicenter, phase III trial. J Clin Oncol 21(6):968-975

15. Chia S, Gradishar W, Mauriac L, Bines J, Amant F, Federico M, Fein L, Romieu G, Buzdar A, Robertson JF, Brufsky A, Possinger K, Rennie P, Sapunar F, Lowe E, Piccart M (2008) Double-blind, randomized placebo controlled trial of fulvestrant compared with exemestane after prior nonsteroidal aromatase inhibitor therapy in postmenopausal women with hormone receptor-positive, advanced breast cancer: results from EFECT. J Clin Oncol 26(10):1664-1670

16. Lønning PE, Bajetta E, Murray R, Tubiana-Hulin M, Eisenberg PD, Mickiewicz E, Celio L, Pitt P, Mita M, Aaronson NK, Fowst C, Arkhipov A, di Salle E, Polli A, Massimini G (2000) Activity of exemestane in metastatic breast cancer after failure of nonsteroidal aromatase inhibitors: a phase II trial. J Clin Oncol 18(11):2234-2244

17. Thurlimann B, Hess D, Koberle D, Senn I, Ballabeni P, Pagani O et al (2004) Anastrozole ('Arimidex') versus tamoxifen as firstline therapy in postmenopausal women with advanced breast cancer: results of the double-blind cross-over SAKK trial 21/95a sub-study of the TARGET (Tamoxifen or 'Arimidex' Randomized Group Efficacy and Tolerability). Breast Cancer Res Treat 85(3):247-254

18. Buzdar A, Hayes D, El-Khoudary A, Yan S, Lønning P, Lichinitser $M$ et al (2001) Phase III, multicenter, double-blind, randomized study of letrozole, an aromatase inhibitor, for advanced breast cancer. Am Soc Clin Oncol 19:3357-3366

19. Tominaga T, Adachi I, Sasaki Y, Tabei T, Ikeda T, Takatsuka Y et al (2002) Double-blind randomised trial comparing the nonsteroidal aromatase inhibitors letrozole and fadrozole in postmenopausal women with advanced breast cancer. Ann Oncol 14:62-70

20. Robertson JF, Osborne CK, Howell A, Jones SE, Mauriac L, Ellis $\mathrm{M}$ et al (2003) Fulvestrant versus anastrozole for the treatment of advanced breast carcinoma in postmenopausal women: a prospective combined analysis of two multicenter trials. Cancer 98(2):229-238

21. Howell A, Robertson JF, Quaresma AJ, Aschermannova A, Mauriac L, Kleeberg UR et al (2002) Fulvestrant, formerly ICI 182,780 , is as effective as anastrozole in postmenopausal women with advanced breast cancer progressing after prior endocrine treatment. J Clin Oncol 20(16):3396-3403

22. Osborne CK, Pippen J, Jones SE, Parker LM, Ellis M, Come S et al (2002) Double-blind, randomized trial comparing the efficacy and tolerability of fulvestrant versus anastrozole in postmenopausal women with advanced breast cancer progressing on prior endocrine therapy: results of a North American trial. J Clin Oncol 20(16):3386-3395 
23. Buzdar A, Jonat W, Howell A, Jones SE, Blomqvist CP, Vogel CL et al (1998) Anastrozole versus megestrol acetate in the treatment of postmenopausal women with advanced breast carcinoma. Am Cancer Soc 83:1142-1152

24. Buzdar A, Jones SE, Vogel CL, Wolter J, Plourde P, Webster A (1997) A phase III trial comparing anastrozole (1 and 10 milligrams), a potent and selective aromatase inhibitor, with megestrol acetate in postmenopausal women with advanced breast carcinoma. Am Cancer Soc 79:730-739

25. Ingle JN, Suman VJ, Rowland KM, Mirchandani D, Bernath AM, Camoriano JK et al (2006) Fulvestrant in women with advanced breast cancer after progression on prior aromatase inhibitor therapy: North Central Cancer Treatment Group Trial N0032. J Clin Oncol 24(7):1052-1056

26. O'Shaughnessy J, Miles D, Vukelja S, Moiseyenko V, Ayoub JP, Cervantes $G$ et al (2002) Superior survival with capecitabine plus docetaxel combination therapy in anthracycline-pretreated patients with advanced breast cancer: phase III trial results. J Clin Oncol 20(12):2812-2823

27. Blum JL, Dieras V, Lo Russo PM, Horton J, Rutman O, Buzdar A et al (2001) Multicenter, Phase II study of capecitabine in taxanepretreated metastatic breast carcinoma patients. Cancer 92(7): $1759-1768$

28. ROTE LISTE ${ }^{\circledR}$ (2007) German drug list (including EU approvals and specific medicinal products). www.rote-liste.de/

29. Einheitlicher Bewertungsmaßstab (2007) http://www.ebm2000plus.d

30. Albert U-S et al (2008) Stufe-3-Leitlinie Brustkrebs-Früherkennung in Deutschland. 1. Aktualisierung 2008. W Zuckschwerdt Verlag, München

31. Gold MR (1996) Cost-effectiveness in health and medicine. Oxford University Press, New York

32. Cameron DA, Camidge DR, Gait CF, Hirsch M (2006) Fulvestrant in the treatment of hormone receptor-positive advanced breast cancer - a cost-effective addition to the treatment sequence. Breast Cancer Res Treat 100(Supplement 1, S231)

33. Drummond MF et al (2005) Methods for the economic evaluation of health care programmes. Cost-effectiveness analysis, $3 \mathrm{rd} \mathrm{edn}$. OUP, Oxford, pp 103-136
34. Uyl-de Groot CA (2006) Economic evaluation of cancer therapies: more and better studies will lead to better choices in cancer care. Eur J Cancer 42(17):2862-2866

35. Arbeitsgemeinschaft Bevölkerungsbezogener Krebsregister (2008) http://www.krebsgesellschaft.de/krebsregister,11268.html

36. Howell A, Robertson JF, Abram P, Lichinitser MR, Elledge R, Bajetta $\mathrm{E}$ et al (2004) Comparison of fulvestrant versus tamoxifen for the treatment of advanced breast cancer in postmenopausal women previously untreated with endocrine therapy: a multinational, double-blind, randomized trial. J Clin Oncol 22(9): $1605-1613$

37. Howell A, Pippen J, Elledge RM, Mauriac L, Vergote I, Jones SE et al (2005) Fulvestrant versus anastrozole for the treatment of advanced breast carcinoma: a prospectively planned combined survival analysis of two multicenter trials. Cancer 104(2):236-239

38. Howell A (2007) Development of endocrine therapy of breast cancer 1896-2006. Geburtshilfe Frauenheilkd 67:595-601

39. DeFriend DJ, Howell A, Nicholson RI, Anderson E, Dowsett M, Mansel RE et al (1994) Investigation of a new pure antiestrogen (ICI 182780) in women with primary breast cancer. Cancer Res 54(2):408-414

40. Howell A (1996) New endocrine treatment strategies. Eur J Cancer $5(3): 2$

41. Warm M, Kates R, Overkamp F, Zaun SG, Harbeck N (2009) Results of the German fulvestrant in practice evaluation programme to evaluate the efficacy, safety, tolerability and acceptance of fulvestrant under daily routine conditions. Cancer Res 69 (Suppl):399s

42. Cameron DA, Camidge DR, Gait CF, Hirsch M (2006) Fulvestrant in the treatment of hormone receptor-positive advanced breast cancer-a cost-effective addition to the treatment sequence. 29th Annual San Antonio breast cancer symposium, San Antonio, Texas, 14th-17th December 2006 